\title{
Features of Pattern \& Light TBI in Social and Mental Health
}

\author{
Sima Mansoori, Mohsen Faizi, \\ Farhang Mozaffar, Bahram Saleh Sedgh pour
}

Faculty of Architecture and Urbanism,

I.U.S.T, Tehran, Iran.

Mansouri.sima@gmail.com

\begin{abstract}
The hidden issues behind the body of Iranian architecture contain meanings, mysteries, and symbols. The aim of this article is to describe the relationship between the function of symbols of Iranian Architecture and the quality of health. This paper investigates 5 case studies namely the traditional bathhouse of Iran (TBI) from 5 cities with a particular approach to light and decorative motifs from the Ghajar and Safavid periods in Iran. The methodology used is the Delphi research with the $Q$ factor analysis. Finally, the profile of the relations of ornaments in a healthy TBI is explained.

Keywords: Quality of Bathhouse, Decorative Motifs, Lighting, Healthy Environment.

eISSN 2398-4279 @ 2018. The Authors. Published for AMER ABRA cE-Bs by e-International Publishing House, Ltd., UK. This is an open access article under the CC BY-NC-ND license (http://creativecommons.org/licenses/bync-nd/4.0/). Peer-review under responsibility of AMER (Association of Malaysian Environment-Behaviour Researchers), ABRA (Association of Behavioural Researchers on Asians) and CE-Bs (Centre for EnvironmentBehaviour Studies), Faculty of Architecture, Planning \& Surveying, Universiti Teknologi MARA, Malaysia.

https://doi.org/10.21834/ajqol.v3i11.123
\end{abstract}




\subsection{Introduction}

The hidden issues behind the body of Iranian architecture contain meanings, mysteries, and symbols. In other words, the ornaments of Persian architecture are defined in a world of symbols. The doctrine of the creation of the traditional bathhouse of Iran (TBI) suggests that the patterns of healthy and healing designs must be extracted and expressed in a language that is comprehensible today.

Poor lighting, uncomfortable illumination, and decorations with an artificial sense of the bathroom makes it a boring environment. lack of vitality, lack of affordance, cold atmosphere are equally unappealing. In the pathology of the bathroom, it should be noted that antiphysiological leisure in a mechanized, and boring environment with no desire to stay for a long time, is the main problem that has prevailed in recent years. The existence of hazards influences our environmental condition and health. The sick building syndrome (SBS), industrial production, and some factors related to building and environment contribute to the increase in health disturbances and diseases. "It has been far more concerned with the pathology of the environment than with the health criteria of the environmental design before the point of decision" (Shoshkes, Ellen.,Adler, Sy, 2009).

It has to deal with the unavoidable qualitative changes in healthcare in the society and living standards to survive over time (Di Cicco, P40). A healing environment can simply describe as the overall environment (physical and non-physical) created to aid the recovery or healing process. (Roslinda, G., Yusoff Abbas, M, 2010).

The "complete wellbeing" of the user includes psychological and physical benefits, which are also the aim of a "healthy building". The well-being of society is the aim of a TBI and is necessary to consider. "The environmental health authority should assess to see if the current practice of placing the health impact assessment under the purview of the Environmental Impact Assessment is still applicable" (Shafie, 2013). The objective of this article is to describe the relationship between the function of symbols, motifs, natural light, and color of Iranian architecture and the quality of health in the TBI. Finally, it is the realization of a "healthy' built environment that takes into consideration the prevention of hazard risks related to health and environment.

\subsection{Literature Review}

\section{Social health}

A "healthy, balanced, and sustainable atmosphere" (Zufiaurre, B., Albertin, A.,Belletich, O., 2014 ) is the most pressing issue in social health. The abundance of public bathhouses in ancient Iranian cities indicate to the approach to healthy is the most important issue. These structures, however, are not mere washing places. These are places where people can also spend their leisure time conversing, exchanging views, resting. Beyond bodily cleanliness, they also provide spiritual refreshment. Optimizing the relationship between the individual and the environment through the Bathroom environment also improves the relation between the society and the environment through the Bathhouse environment (Ganjnameh, 2008). The work of the Peckham Health Center has shown that health is not brought about by drugs, 
vitamins, or by developing muscles in the body. It is the result of an active life in an environment rich in various opportunities for mental and physical development with free and friendly social intercourse. Healthy people do not want to organize, but they do want opportunities to do things together (J.Tyrwhitt, 1985). It is a convergence between a long epidemiological tradition that examines the inter-relationships between disease agents, characteristics of the host, and the broader socio-cultural and environmental context. The current interest in the promotion of health and a safer environment recommends a modification of how we live in and relate to the social world and nature (Shoshkes, Ellen.,Adler, Sy., 2009).

\section{Mental health}

Ravan is the psychological aspect of human beings, which is more important than Jesm in designing any building. Therefore, a dwelling should be built considering its psychological impacts on the human brain and the nervous system. Based on the concept of psychosomatic diseases, any form, pattern or element that negatively affects the Ravan, will lead to health problems for the inhabitants. Psychology considers and deals with the psychological effects of forms, patterns, spatial organizations, color, light, and plant motifs (Goodarzi, Ali.,Fazeli, Hengameh, 2014).

\section{The quality of Life}

"Equation conveys two primary meanings. The first is an imprecise sense of harmonious or aesthetically pleasing proportionality and balance; such that it reflects beauty or perfection, which links between a human being and architectural design" (Mahdavineja, M., Mansoori, S, 2011).

Energy flow extends from the surface of the human body to energy centers of the body, and the body absorbs fresh energy and expels the used up energies (Leadbeater, 1972). Some places have positive energies to carry the "Ravan" placed at the center of the brain then the Ravan absorbs them, distributes, and energizes the whole physical body. The energy centers control and handle the proper functioning of the whole physical body and its different parts and organs (Powell, 2005; Sui, 2006; Sui, 2009).

\section{Ornament in TBI}

The Bineh or Sar-Bineh is the largest and the most ornate area of a bathhouse; it is a large, elaborately decorated hall with a large dome and a central pool. The central area of the Bineh surrounded by platforms or alcoves where visitors can sit and rest. The floor of these areas is higher than that of the Bineh's central area, and it usually has a shallower ceiling. Thus, it forms comfortable, secluded areas with a commanding view of the central area. The uniform lighting of the Bineh also adds to the impact of this decoration, while pools with water spouts further enhance the restful atmosphere of this field by their brilliant colors and rustling sounds. (Ganjnameh, 2008). 


\subsection{Methodology}

This paper investigates 5 case studies of TBI from 5 cities (Table 1) with particular emphasis on light and decorative motifs from the Ghajar and Safavid periods. The healthy approach needs to be analyzed, decrypted of the intrinsic properties, and healthy principles of how it affects the TBI will be extracted. The research method will scrutinize and measure how the ornaments influence healthy minds. Using the Delphi method and the SPSS software version 22, reliability and validity assessment of the research data performed. Evaluation and Survey analysis of the data obtained from the quantity measurements be carried out by the $Q$ factor analysis. Dimensions analysis among components of the case studies (samples), components of the buildings, and the correlation between the factors be performed. Finally, the profile relations and process profiling of the ornaments in a healthy TBI drawn, and the final effective factors explained. Moreover, evaluation of fitness, direct qualitative measures, and indirect relations between those parameters performed. A healthy profile of the built environment determined.

Table 1: Chosen Bathhouse for Coding. Source by Author:

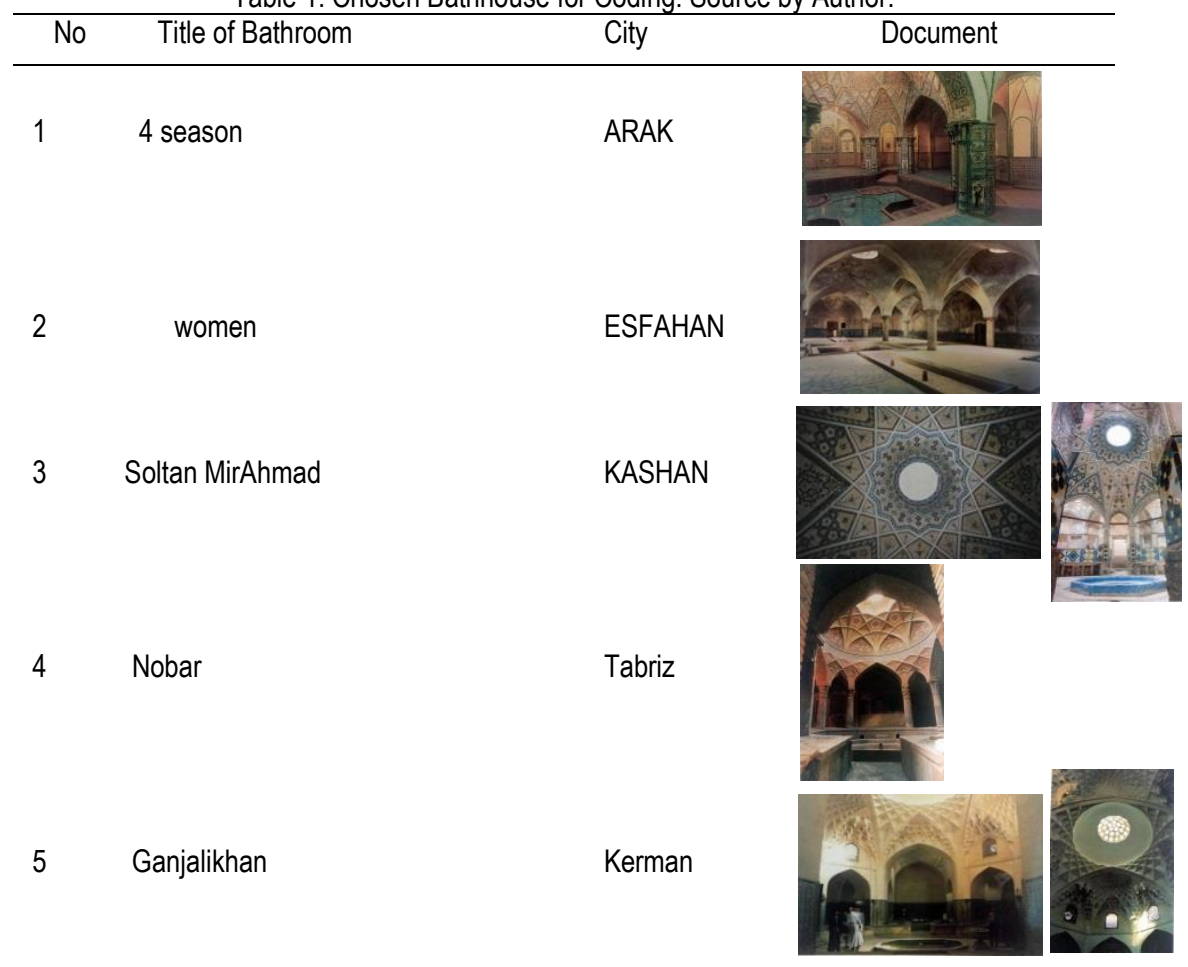




\section{The number of case studies (samples)}

The five bathhouses (case study) have a different approach to ornaments and use various colors in different climatic conditions. Samples with specific characters were selected as listed below:

1. Sarbineh 4 Fasl Arak: Full of color ornaments and decorative motifs (seven colors);

2. Garmkhaneh women Esfahan: Pure and unique ornaments via Saroj and light in particular;

3. Sarbineh Soltan MirAhmad Kashan: Moderate ornaments with brick and tile;

4. Garmkhaneh Nobar Tabriz: Original ornaments with red bricks; unique and extraordinary ornaments in the TBl; and

5. Sarbineh Ganjalikhan Kerman: Majestic simplicity; spiritual lights with integrity and purity. ( Table 1)

Interviews with samples performed among six experts including architectural professors, professional restorers, and psychological professors. Semi-structured interviews performed with 6 of the best professors who are experts in the area of the traditional bathhouse of Iran.

After that, a table of the specification was crystallized from the relations between the categorized concepts and the components. Accordingly, a questionnaire with 90 questions was prepared and filled up by $20 \mathrm{Ph} . \mathrm{D}$. students consisting of architecture graduates and professional architects.

The samples' adequacy was measured using the Kaiser-Meyer-Olkin (KMO) and Bartlett's Tests, and the result were 0.94. Therefore, these samples are sufficient for this paper. ( Table 2)

Then, all the data analysed by $Q$-analysis factor. The classification of a conceptual vision of the relation between concepts and categories created. the statistical society was classified into three groups of $80 \%, 15 \%$, and finally, $5 \%$ of the total. (Figure 1)

Table 2: KMO and Bartlett's Test. Source by analysis of spss 22

\begin{tabular}{|c|c|c|}
\hline \multicolumn{2}{|c|}{ Kaiser-Meyer-Olkin Measure of Sampling Adequacy. } & .946 \\
\hline Bartlett is Test of Sphericity & Approx. Chi-Square & 1723.851 \\
\hline & df & 190 \\
\hline & Sig. & .000 \\
\hline
\end{tabular}

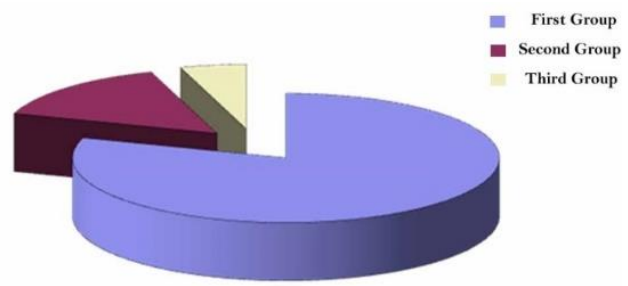

Figure 1: Distribution graph unanimously participant (Source:by authors) 


\subsection{Findings and Discussions}

\section{Result of the first group ( $80 \%$ of the total)}

- 93\% of the first group of participants confirmed the relation between mental health and a guided look towards the light, wide and generous space, and the relation between beauty and the light of the hypocaust.

- $87 \%$ of the first group of participants emphasized the relation between beauty and order of surface ceiling, creativity in the use of color and light and a pleasant environment. Moreover, they pointed out the relation between quality of the environment and the Gestalt approach, coordination between structure and ornament.

- In the first group, $81 \%$ of the total said that there is a meaningful relation between mental health and the feeling of lightness and convenience. Relaxation and spiritual presence of light are as well as the relation between beauty and originality of the motifs and decoration, an organization of motifs, light, color, and structure. Moreover, the relation between quality of the environment and playing with the light has been mentioned.

- $75 \%$ of the first group of participants pointed out the quality of environment and unity between ornament and spatial structure, liveliness, and height of a ceiling. Moreover, the relation between social health and unity in diversity, colors, and motifs has been indicated. Also, they mentioned the relation between beauty and partial and total congruence.

- $68 \%$ of the first group of participants pointed out the relation between social health and friendly atmosphere, as well as the relation between mental health and the combination of light and material. They also indicated the relation between quality of environment and light, simplicity, and purity of space. They also mentioned the relation between mental health and security. (Figure 2(a))

\section{Result of the second group ( $15 \%$ of the total)}

Firstly, $100 \%$ of the second group of participants confirmed the relation between mental health and a feeling of lightness, convenience, fun and enjoyable, and light. Moreover, the second group of participants emphasized the relation between beauty and the congruence of structure and ornament as well as the relation between social health and friendly environment. (Figure 2(a))

Secondly, they approved the relation between quality of life at the bathhouse and a combination between light and material.

Thirdly, they mentioned the relation between beauty and originality of motifs and brick ornament, and order and creativity in the color and motifs.

Fourthly, the second group pointed out the relation between mental health and the guided look toward the light, beauty and the emphasis on rhythm and pivot points. Moreover, they emphasized on social health and contrasting colors and magnificent space.

Finally, all of the participants of this group indicated the relation between beauty and presence of sunlight and ornament without diversity of colors. They also confirmed the relation between quality of life and playing with sunlight in the bathhouse, high ceiling and using the contrast of colors between ground, wall, and ceiling. Moreover, in this part, they emphasized the relation between mental health and a welcoming, wide, and generous space. 
(Figure 2).

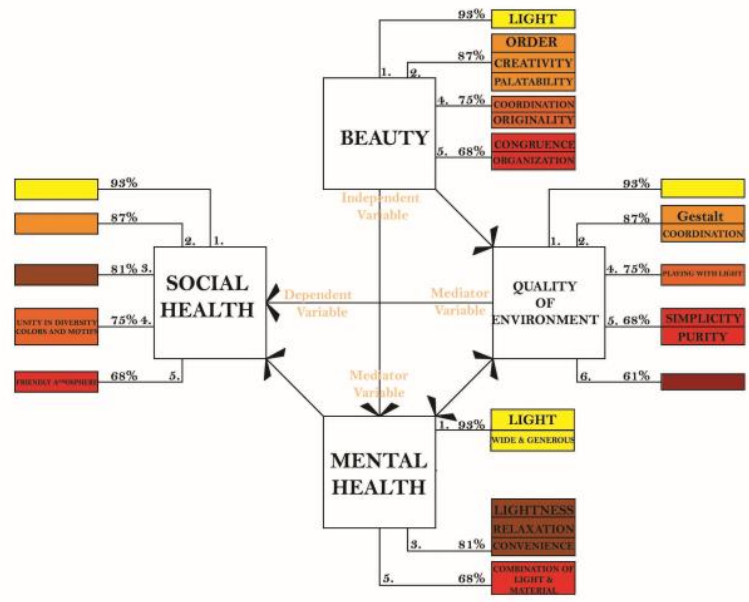

Fig. 2 (a) Result of the first group (Source:by authors)

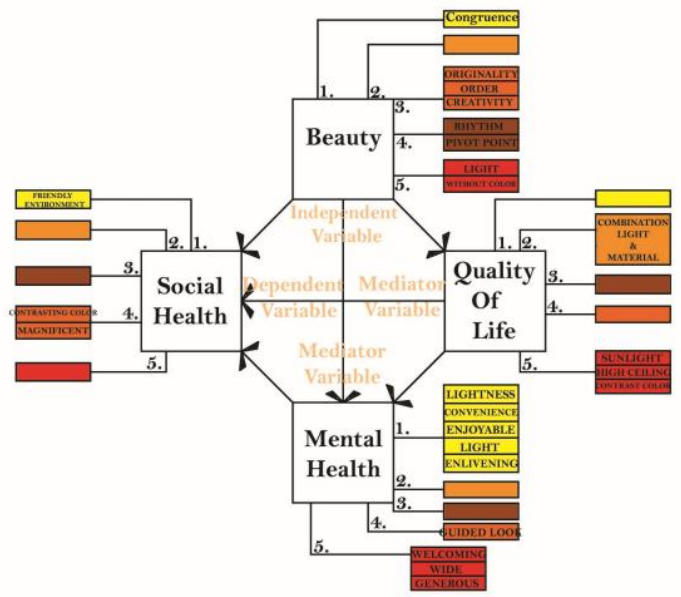

Fig. 2 (b) Result of the second group (Source:by authors)

In this paper, $\mathrm{TBI}$ is not only considered regarding visual beauty but also through the application of physical, mental, and social health aspects and the investigation of colors, motifs, and decoration on the quality of life in the environment. The TBI strives to produce comfortable environments for the prevention of mental problems with a high level of social 
interaction with fun times, intangible prevention, and healing. In other words, intangible social sustainability has a common meaning with intangible healing and a therapeutic place. The presence of sunlight with full-spectrum light healing figures and pictures develop health and prevent diseases. It is necessary to not only present but also to reuse and update the traditional therapeutic principles. In TBI, particular components of design focus on optimizing the relationship between the individual and environment. To promote contact with a great social group and socially-friendly interactions, in Sarbineh and Garmkhaneh, there is a social human scale. Therefore, they have many ornaments, motif decorations, and ceiling heights.

On the other hand, in "Miandar", "Khazineh", "Khalvat" and "Chalehooze", we observe individual human scales. There is a suitable, private place for hygiene and individual cleaning without motifs, decorations and ornament promotions, and an empowered architectural space for healing purposes.

\subsection{Conclusion}

By revealing the meanings of the ornaments' symbols used in the construction, the environment can promote the quality of the environmental life. On the other hand, the definition of "property of decorative motifs" in TBI is comparable with the definition of the "quality of the bathhouse" in the mind of the Iranian artist. In other words, an embroidered body of the bathhouse with the geometric motifs, and timeless symbols is a part of the anonymous qualities. The compatibility of drawing, light, and color among most of the TBI recall the "feeling of being in Paradise" among the users.

Not only are psychological benefits provided by the effect of natural light (NL), decorative and painting motifs but social health also improves more and more in the friendly and lovely atmosphere. It is the key to discovering a new function for the bathhouse. (Figure 3(a))

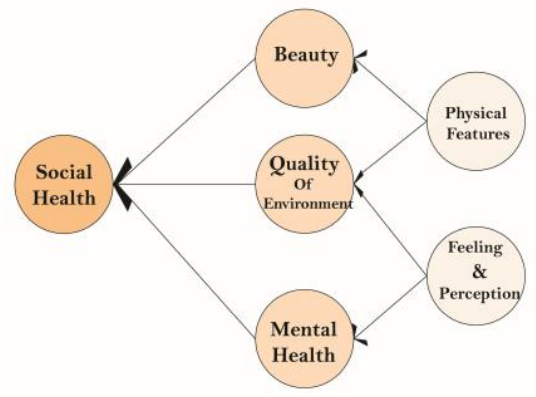

Fig. 3 (a) Profile of the first group

(Source: by authors)

The investigation concluded that the first group indicated that natural light $(\mathrm{NL})$ affects the beauty and mental health more than motifs, decorations, and colors. $81 \%$ believed that physical and cognitive features have a meaningful relationship with beauty and the quality of the environment. Also, $81 \%$ believed that feeling and perception of space have an effect on 
mental health. Therefore, in this paper, beauty is known as the independent variable, and the quality of the environment and mental health is the mediator variable. Finally, social health is the dependent variable.

In the second group, an advanced attitude was found on this issue. Firstly, they found that the physical features of the TBI such as the decorative motifs and natural light influence the human feelings and perception about physiology and psychology. Then, these perceptions are distributed and scattered in the society, and the society beliefs crystalize. Finally, mental and social health leads to a friendly atmosphere in the TBI, and with the repeated use of the $\mathrm{TBI}$, the legibility of the TBI becomes better, and there is a friendlier environment for users and the environment of TBI. As it showed in second profile, friendly environment has affected in mental perceptions; and in this profile like a rotation cycle, it continues. Therefor legibility and friendly atmosphere become better and more. (Figure 3(b)) Intangible social therapy observed in the environment including entertainment with a friendly atmosphere, home-like convenience, and a place for conversation

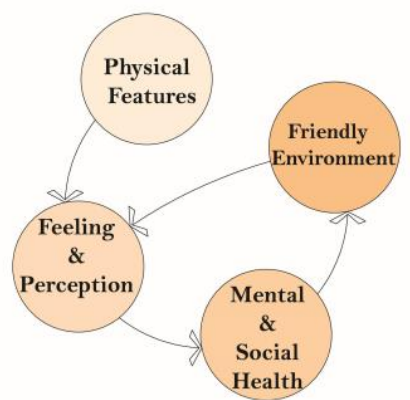

Fig. 3 (b) Profile of the second group

\section{Further Research}

(Source: by authors)

- To investigate the association between these findings and the modeling of a healthy TBl; and

- To compare the effectiveness of the TBI and similar Turkish and Roman bathhouses about the current issue.

\section{Acknowledgement}

Our heartiest gratitude prof Hossein Kheyrandish for stimulant the research in making this study possible.

\section{References}

Ayuni Shafie, F., Omar, D., Karuppannan, S.(2013). Environmental Health Impact Assessment and Urban Planning. 
Procedia - Social and Behavioral Sciences. Publish By ELSEVIER.p:82.

Di Cicco, Simona.(2004). Well-Being in Hospitals.Design aids for Functionally -Environmentally-sound Therapeutic Buildings. Eindhoven University Press.p:74.

Ghazali, R., Yusoff Abbas, M.(2012). Paediatric Community: Healing Environment Conducive Enough? Procedia Social and Behavioral Sciences. Publish By ELSEVIER.p:42.

Goodarzi,A., Fazeli,H.(2014). Identifying the Principles of Traditional Iranian Architecture in the Light of Vastu Shastra, the Traditional Indian Wisdom. Journal of Design and Built Environment Vol. 14,p: 1,2.

Leadbeater, C. W. (1972). The Chakras. Quest Books.

Mahdavineja,M.,Mansoori,S.(2011). Architectural Design Criteria of Socio-Behavioral Approach toward Healthy Model. Procedia - Social and Behavioral Sciences. Publish By ELSEVIER.p:476.

Shoshkes,Ellen., Adler, Sy.(2009). Planning for healthy people/healthy places: lessons from mid-twentieth century global discourse. Planning Perspectives, Vol. 24, No. 2,pp: 198, 202, 210. Routledge.

Sui, M. C. (2006). Miracles Through Pranic Healing: Practical Manual on Energy Healing. Philippines. Institute for Inner Studies Publishing Foundation.p:6.

Sui, M. C. (2009). The Chakras and their Functions. Bangalore. Institute for Inner Studies Publishing Foundation India Private Limited.

Tyrwhitt,J.(1945).'Town Planning', in Architect's Year Book, ed. J. Drew (London, Paul Elek).p: 22.

Zufiaurre,B.,Albertin,A.,Belletich,O.(2014). Education for sustainable, healthy development. Procedia - Social and Behavioral Sciences 132. Publish By ELSEVIER.p:196.

Zufiaurre,B.,Albertin,A.,Belletich,O.(2008).Bathhouses. GANJNAMEH. Published: Rozanne.p 7. 